\title{
An Efficient Framework based on Emotional Intelligence to Improve Team Performance in Developing Countries
}

\author{
FaizaAyub Syed \\ Department of Software Engineering, University of Engineering \& Technology, Taxila, Pakistan \\ Email: faizaayubsyed@yahoo.com \\ Adeel Rafiq \\ Department of Software Engineering, University of Engineering \& Technology, Taxila, Pakistan \\ Email: adeel_leo_86@hotmail.com \\ Bilal Ahsan \\ Department of Software Engineering, University of Engineering \& Technology, Taxila, Pakistan \\ Email: bilal_ahsan46@yahoo.com \\ Muhammad NadeemMajeed \\ Department of Software Engineering, University of Engineering \& Technology, Taxila, Pakistan \\ Email: nadeem.majeed@uettaxila.edu.pk
}

\begin{abstract}
In Project management, team's motivation is one of the most important factors in the success of a project. Project Managersmanage the whole project by assuring that all the members are performing the duties they are assigned. Emotional Intelligence is the ability to identify the attitude of a team member towards a project. In developing countrieslack of emotional intelligence factors may cost people their jobs. In this paper conflict management, technical management, interest development and stress management problems are discussed with reference to developing countries and an efficient approach to resolve these issues is also proposed. Therefore project managers should raise their EI (emotional intelligence) and also help members to raise their EI. This paper explores the related work in EI, and then finds the useful Emotional Intelligence factors which are appropriate for the project manager. Then this paper also determinesa framework which is useful for project managers.
\end{abstract}

Index Terms - Emotional Intelligence (EI).

\section{INTRODUCTION}

The term Emotional Intelligence was first coined by Wayne Payne in his doctoral thesis "A study Of Emotion" in 1985. Emotional Intelligence emerged as an influential field in late 1990's. The leading researchers in this field since 1990's are Peter Salovey and John D.Mayer [1]. According to them the classification among people is done by monitoring one's own and others emotions and thoughts and then reusing this information for steering one's actions and emotions. EI helps people to gain success and happiness by achieving their personal and professional goals [2]. EI concept was more popularized by Daniel Goleman in his book "Emotional Intelligence" in 1995. Later on EI needs to be present in every field. EI has five major components. These components are shown in fig 1 . The most necessary among these components is selfawareness [3].

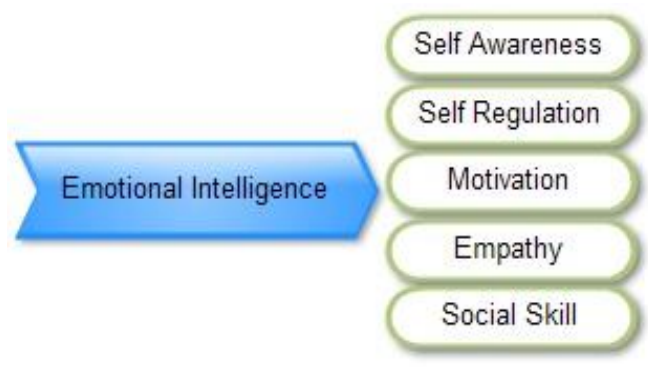

Figure1. Components of EI

For building EI one should start with himself. He should keep aware of his feelings and thoughts. He should manage his emotions and should react to people in a positive manner. People who develop EI can groom their both personal and professional skills. Selfawareness and effective communication skills should be developed in people. An important aspect of EI is to think positively and help people to understand their goals and objectives. People should also develop the habit of social awareness along with self. Social awareness makes people aware of their surroundings at organizational as well as non-organizational level. Social skills help in building and maintaining relationships. A vital problem at organizational level is to understand the feelings and emotions of others. To 
understand others you have to be empathetic. Building motivation and self-regulation with open mind and optimistically results in achieving best results [4].

One of the fields deeply linked with EI is project management. A project manager should have a deep understanding of EI as well as the ability to program schedules and make financial arrangements. To understand project dependencies project managers should need to discuss, manipulate and maintain partnership with other teams. To be efficient in a matrix environment an effective skill of project manager is that they should maintain better relationship with others in order to obtain the best result. Making efficient team is one of the key responsibilities of project manager. Managers should have the ability to motivate his team members, resolve conflicts, improve the technical and non-technical performance of team members and understand people and their needs. Project managers should have strong leadership ability so that they can cope and interact with the team members and stakeholders. Project manager should keep track of project for managing project and understanding the emotions of team members [5].

Project managers, project leaders and team members should learn to adapt EI in project environment. Emotions should be used as a source of information. Self-awareness should be promoted among the whole team. Strengths and weaknesses related to EI should be monitored. For becoming a successful project manager it is necessary to build and maintain an effective relationship with project team and stakeholders [6].

The paper is organized as follows: Section I is the introduction of EI and its linkage with project management. Section II presents the literature review. Section III describes the challenges faced by a project team in developing countries. Section IV presents solution to the challenges discussed in section III. Section V is conclusion of research.

\section{RELATED WORK}

The study focused on [7] demonstrating linkage between EI and the challenges faced by virtual project managers. The study reveals that there is an existence of relationship between Emotional Intelligence (EI) and challenges/elements of Virtual Project Management (VPM). According to Goleman the success of a project is dependent on the emotional intelligence of its managers. Emotional intelligence of managers helps them in building relations with the workers which can result in improving the success by $1 \%$ to $2 \%$.The major challenges faced by virtual teams are culture, communication and project management. While working with others Emotional intelligence means how well you understand the emotions of others. Understanding others' emotions can result in building good relations with them which can be helpful in knowing others opinions and their interests in the project. In Virtual Project Management multiple virtual teams interact with each other to achieve the specified goals. Good emotional intelligence can result in decrease of more than $50 \%$ faults which cause project failure. In VPM good self-control in Emotional Intelligence can be achieved by staying focussed.In VPM you need to think clearly and stay focused which is self-control in EI. This element of EI is related to the challenge of trust, adaptability and change, innovation and motivation in VPM. To lead effectively managers should take feedback from others and respond to it in an efficient manner. To improve the emotional understanding of the employees, cultural and personal events should be celebrated.

According to this survey [8], in which more than 5000 participants participated, more than $90 \%$ had the opinion that in 21 st century managers should have the ability of emotional intelligence. Emotional intelligence comes with time. Thus for the success of projects all the project managers must be taught the ways to improve their emotional intelligence.

Tang and Yin [9] discusses various characteristics of Emotional Intelligence (EI) that exists among different organizational groups. They study the characteristics among two college groups of information technology and management students. These EI characteristics are measured by conducting One-way analysis of Variance (ANOVAs). They presented Emotional Skills Assessment Process (ESAP) to identify skills, knowledge, value and articulation of human emotions in vigorous and creative ways. EI helps in building emotional talent and EI elements like assertion, power, obligation, time management, stress management, and direction alteration. Measurement of these six building elements of EI is done using ESAP. In order to analyze the significant differences between these elements among the two student groups; analysis is conducted using ANOVAs. Using this method they handle three types of cases i.e. valid, missing and total cases for measuring the suitable response rate of EI elements. The analysis stage helps in examining the major differences in six elements of EI and the overall EI that exists between the two selected groups. The results of analysis indicate that IT students prefer work community rather than maintaining organizational relationships. At the cost of their personal well-being they can handle complex situations and schedule work pressures from multiple working communities in organization. However, IT students have lowest rating score in the assertion element of EI as compared to other group. IT students should need to develop skills of communication and interaction for better assertiveness.

A framework is presented in this paper [10] that focuses on the contribution of emotional intelligence in the success of a project. The impact of emotional intelligence in team development, leadership and conflict resolution is given significant importance. Test models were developed to assess how an individual perceives emotions and understands others emotions. When one is able to understand his as well as others emotions, he can be a leader to create an environment in which there are open commutations and trust worthiness. 
This concludes that success is not only dependent on pure technical skills but also on how well you get cooperation from others, how well you understand others or simply what the overall emotional intelligence level is.

In this paper [11], Emotional Intelligence and Intelligence Quotient are relevant to each other. IQ is helpful for leaders in grasping their necessary skills and tools. Emotional intelligence has some common features which are EI of every individual; on average the EI level in the team, self-estimate and self-management of team etc. Like all other literatures this paper also focuses on the point that success of a project is very much dependent on the level of EI. The teams having higher emotional intelligence perform very well in contrast with those having low level of emotional intelligence. While a team is discussed the EI of whole team is important for the success rate rather than the EI of an individual. So the team members must coordinate with others to increase the level of EI of the whole team while avoiding factors like jealousy etc. The leaders' characteristics play an important role in building the EI level of the team. If he is honest and frank, this will create frankness between the whole team and an honest culture.

Raza and Nisar [12] suggested that for an effective leadership EI is a key to success. They predict that an optimistic link exist between EI and leadership. Their area of research is based on personality development. The aim of this research is to determine the impact of EI on leadership. Survey of different organizational leaders is conducted using a leadership tool TEIQue. This leadership tool is used to measure different traits of EI involved in personality development. Analysis of EI on the basis of gender results that factor of global EI in men is better as compared to women. On the other hand leadership traits in female are better. At organizational level managers with mid age can control and manage emotions in a better way. With the passage of time EI boosts during different stages of relationship whereas effective leadership behaves in a reverse pattern. Managers with highest qualification exhibits best effective leadership persona. Other variables like adaptability, social ability and motivation are strongly interrelated to EI. The results of analysis indicate that a variation of 26 percent between effective leadership and EI has been explained.

\section{PROJECT TEAM CHALLENGES}

We have proposed a theoretical framework that highlights various challenges faced by project manager and his team. Then we suggest solutions to these challenges by interlinking them with EI.Factors like interest development, mutual understanding, conflict management and time management are some of the major challenges which are difficult to handle without EI. Moreover, this framework helps the project manager for driving his team to achieve a progressive rate of success.
Success of project is not only dependent on the technical abilities but on the EI as well. For example if there is no interaction between team members and everyone has his different opinion about how to achieve the goal, it can cause conflicts and may result in excessive loss of time.A brief detail of major challenges is described below.

\section{A. Interest Development in Project Team}

It is very easy to understand that if someone takes interest in something, it is very likely to be achieved. In software projects it is very necessary that the project is interesting for the whole team otherwise the work progress will be slow and success rate will be low [6]. This is the responsibility of the project manager to understand which team members are interested in the project and which are not. And develop interest in those members which are not interested. There could be several reasons due to which team members lack interest. It could be:

- The difference in opinion about how to achieve the result

- The experience of the team members might be different than the required field

- Lack of interest could also be due to the personal clashes among team members.

\section{B. Conflict in Project Team}

One of the major challenges for project leader is team conflict [13]. The key causes of conflict among project teams arise due to disagreement on goals, wrong project priorities and conflicting working agendas. In organizations multiple projects are running at the same time. Team members may sometimes report to senior management along with functional managers. This may higher the rate of conflict. Some common reasons for conflict occurrence are:

- Communication gap

- Inaccurate flow of information

- Complex relationships

- Lack of resources

- Meet deadlines according to demands

- Misunderstandings and difference in opinions

- Timely completion of project

Conflicts may be drawn in cross functional high technology environment where one team is dependent on the other team to get their tasks done.

\section{Stress in Project Team}

Project team stress is a vital problem because it affects the effectiveness of whole team [14]. It is necessary to identify the causes of stress as early as possible so as to reduce the possible side effects. The major causes of stress origin in project team are:

- To work in restricted time, cost and quality limits

- To work in a recurrent varying environments

- When relative complexity of projects tend to increase 
- When conflicts appear among the team members

- When personal problems of team members arise

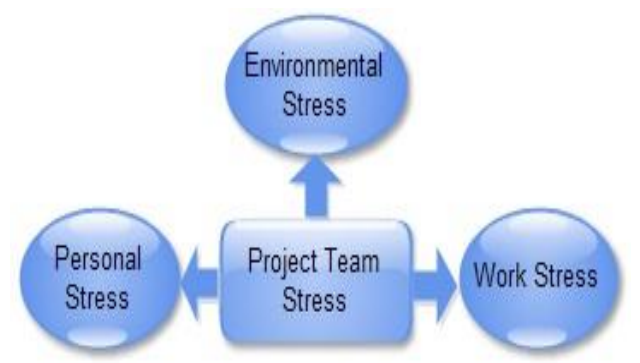

Figure 2. Types of Stress in Project Management

Types of stress [14] that project teams usually undergo are shown in fig 2 . A brief explanation of stress types and symptoms associated with them is given below.

C.1. Environmental Stress: The organizational internal and external factors are greatly involved in causing environmental stress. Some noticeable examples are: fear of joblessness, change in technological trend, new working policies and change in economic level.

C.2. Work Stress: It instigates from the working environment. The main reasons that cause work stress include: high workload on employees, rate of individual responsibility too high, conflict development, and leadership conscientiousness.

C.3. Personal Stress: The issues with in the project team raise the level of personal stress. This type of stress originates due to several personal problems faced by project team. These problems are unable to be controlled by project manager.

People experiencing stress undergo a lot of problems. The level of performance of stress takers decreases with time if they don't take precautionary measures before time. The many symptoms associated with above mentioned stress types [14] are grouped into three categories as shown in fig 3 .

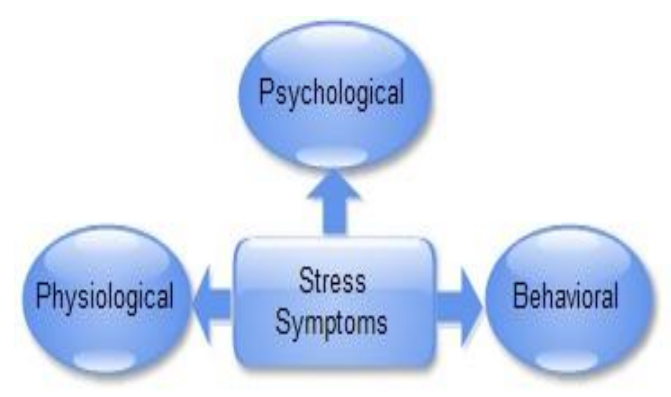

Figure 3. Stress Symptoms in Project Team

Symptoms like high blood pressure, changes in heart rate, headache and visual disorder are all Physiological symptoms. Loss of memory, sleeplessness, depression and nervousness are common examples of Psychological symptoms. Behavioral symptoms include overall loss of interest in work, loss of energy, increase in absenteeism and change in working style.

Project manager should interact with people to help solve their problems in-order to build an efficient team.

\section{PROJECT TEAM AND EMOTIONAL INTELLIGENCE- SOLUTION TO CHALLENGES}

This section contains solutions to challenges discussed in previous section. Studies reveal that EI is deeply linked with project management. The success of a project is largely dependent on EI and technical abilities of project team. Technical abilities or skills basically relate to particular job requirements. A team having good technical aptitude but no EI have a lower performance level. On the other hand EI is an ability that helps in understanding and realizing the thoughts and emotions of team members and utilizing these thoughts for boosting the work progress. A team with strong technical proficiency along with EI is at top performance [15]. A team having good project leader can progress well. Leadership is a way of social interaction. It is a process in which leaders tend to recognize, evoke and manage the emotional state of his team. A leader whose emotional skills are high can effectively and smoothly interact emotionally with his team [16].

At organizational level leaders should develop intrapersonal and inter-personal skills in his team.The EI skill pyramid needed for project management is shown in fig 4.

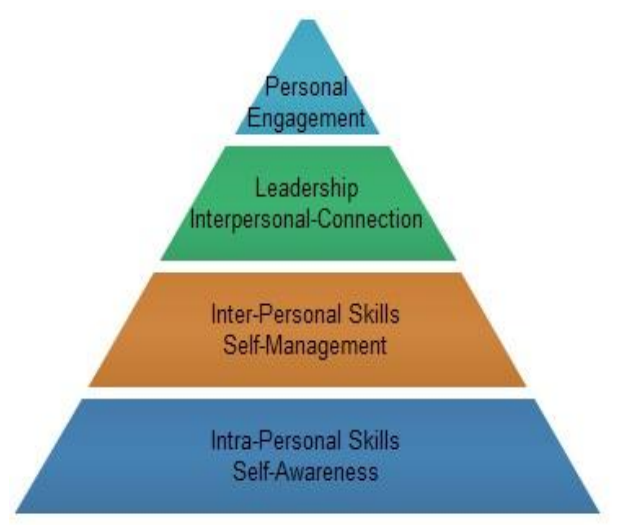

Figure 4. EI Skill Pyramid for Project Management

The EI skill pyramid of project management relates Intra-Personal skills to self-awareness, Inter-Personal skills to self-management and leadership and personal engagement. All these form the basis of an emotionally intelligent team.

\section{A. Interest Development through EI}

EI has a great impact on interest development. Loss of interest in work causes dissatisfaction and puts a bad impression of person among team. We have suggested a three factor triad for interest development shown in fig 5 . Developing interest in team is largely dependent on 
friendliness, mutual relationship and understanding among team. These factors are described below.

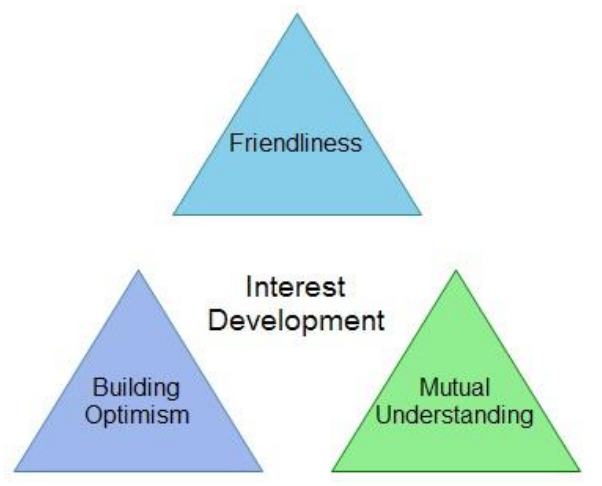

Figure 5. Three factor triad for Interest Development

\section{a. Friendliness}

Team members who are undergoing hard time while learning some of new skills may lose their interest in work due to comfortableness. In order to avoid this problem the team leader should promote a friendly environment. He should understand the emotions of team members who are facing problems. On the other hand team members who are working well should slow their pace to match with others. The whole team cooperates with members who are facing problems and help them in finishing their work on time. This results in high team performance.

\section{b. Mutual Understanding}

Team members may lose their interest when clashes appear among the team. This may be due to difference in opinions or other reasons like professional jealousy, personal problems and lack of emotional understanding. Relations are linked with emotions. For developing mutual understanding one should be emotionally intelligent. He should has the ability to understand and recognize others feelings and emotions. In this way he can easily develop mutual understanding among team. Mutual understanding promotes the feelings of harmony among the team.

\section{c. Building Optimism}

Team leader should lead his team in an optimistic manner. Building optimism is an essential part of EI. For an optimistic approach self-disruption and illmannered behavior and statements should be avoided. Team should develop a rationale for solving issues in an optimistic way. Lack of optimism causes dissatisfaction among team.

\section{B. Conflict Management through EI}

People with high rate of EI engage in conflicts in a healthier way. In teamwork everyone's view should be respected during communication. Resolving conflicts in such a way creates healthy environment with in a group where everyone can share his views individually. This not only resolves conflicts but also strengthen the team lead.

\section{B. 1. An 8 style approach for conflict Resolution}

We suggest an eight style approach for conflict resolution as shown in fig 6 . Project manager with high EI uses these styles based upon the type of conflict occurred. A brief explanation of these styles is given below.

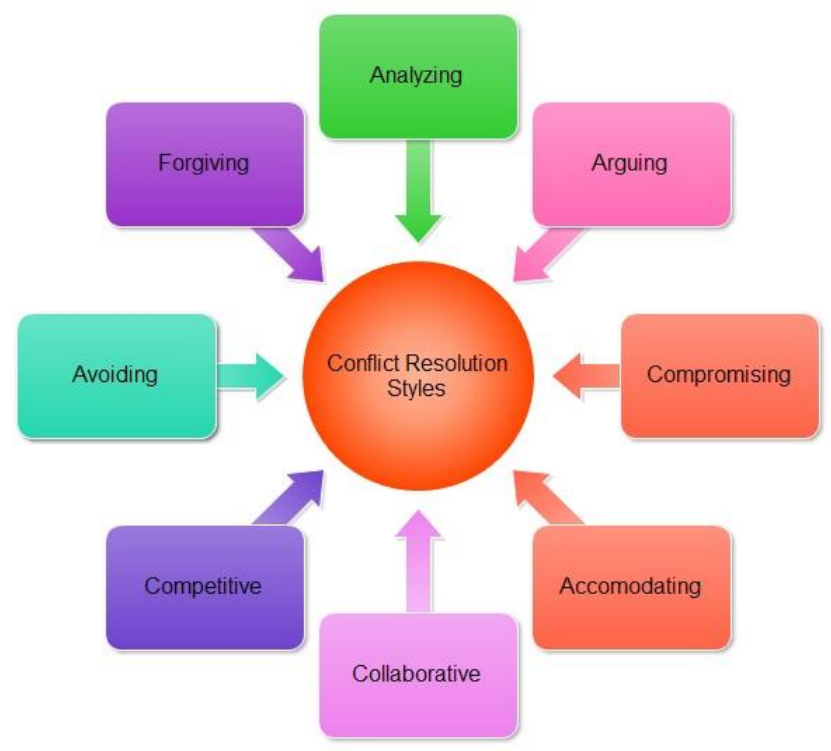

Figure 6.An 8-style approach for Conflict Resolution

\section{a. Analyzing}

In this style the conflicting situations should be analyzed first. This results in better identification and management of conflicts.

\section{b. Arguing}

In this style people cite proofs and reasons for persuading others to settle at a common solution. Resolving arguments take a lot of time, effort and energy. One should consider only worth arguments instead of wasting time on useless arguments. This style is used when the team has enough time and resources.

\section{c. .Compromising}

In this style the conflicting parties bargained for solutions to problemthat helps in satisfying people to some extent. Compromise can be taken as both win-win and lose-lose approach since both parties will either get something and neither party will get the complete thing.

\section{d. Accommodating}

In this style an attempt is made to lessen the emotion that subsists in the conflicts. Conflicts can be subsisted by highlighting concerned and non-concerned issues. This style is usually used in situation when stakes are low, when harmony and continuity in relationship is given more priority.

\section{e. Collaborative}

In collaborative style the conflicting parties meet face to face to resolve their conflicts. During meetings focus is on solving the problems rather than getting aggressive and giving arguments. This style is used when skills of 
both parties compliments each other, when there is enough time to understand each other, when trust and confidence exist in teams.

\section{f. Competitive}

In this style the one of the conflicting party take a firm stand. It usually results in a win-lose situation in which one party wins at the expense of others. This style is used when a quick decision is to be made, when harmony and relationship is unimportant.

\section{g. Avoiding}

This style is used when conflicting parties are willing to delay the situation temporarily. Usually this situation arises when both parties feel that they cannot win.

\section{h. Forgiving}

In this style the major focus is on promoting healthy environment where mutual respect of each team individual is maintained. No conflict style will work if mutual respect factor is degraded.

These conflict resolution styles help in managing conflicts by promoting emotional intelligence in team members.

\section{Stress Management through EI}

EI and stress management are modules used for selfdevelopment. Pressure is a part of every activity we do in everyday life. It can be motivating certain times. When pressure increases to a certain limit where human being feelings and ability to perceive does not cooperate with each other results in stress.

With increase in stress awareness stress counselors focus on managing different types of stress associated with people belonging to different workgroups. Team leader should be a good counselor. We have suggested nine rules for managing stress in project team in connection with EI as shown in fig 7. These rules are described below.

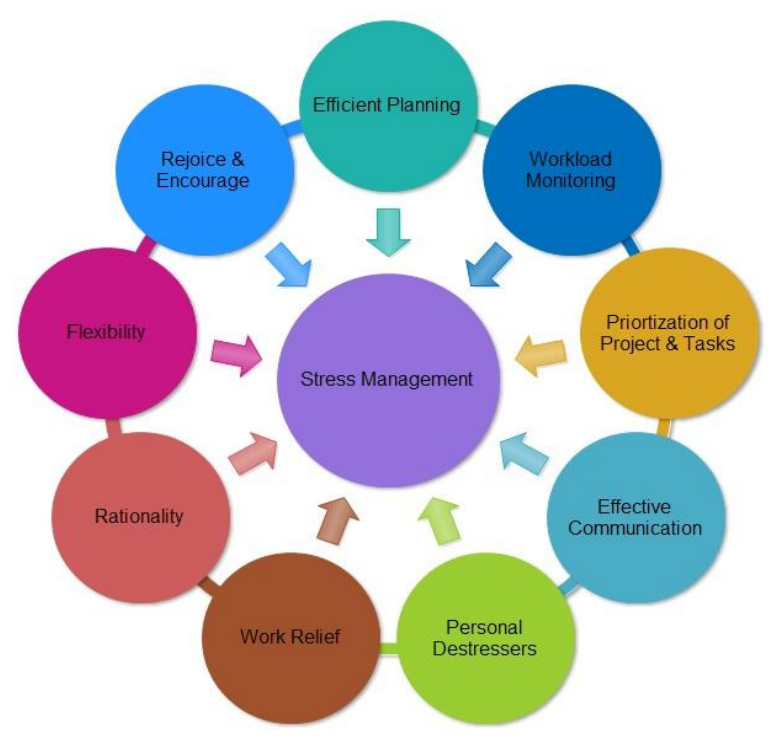

Figure 7. Nine Rules for Stress Management

\section{a. Efficient Planning}

Problems and issues arise due to inefficient planning done at improper time. In order to avoid stress problems proper plans should be developed.

\section{b. Workload Monitoring}

Throwing tons of work on project team members made them stressful. If lot of work is assigned without appropriate management, then the team cannot produce quality work. Workload should be assigned properly on time to avoid stress.

\section{c. Prioritization of Projects and Tasks}

When there is a pile of work to do it becomes stressful for the team. Unorganized work lead to misunderstandings; so in order to reduce stress and misunderstandings, work objectives should be cleared; projects and tasks should be prioritized for efficient working and stress removal.

\section{d. Better Communication}

Communication is a most important element for reducing and avoiding stress. Lack of effective communication is an important contributor towards stress development. Team leader should empathetically listen to each team individual problems. This will help the leader in sensing the emotional thoughts and feelings of his team. Communicating well with the team helps in reducing the members stress.

\section{e. Personal distresses}

Team members should be given time to encourage personal distresses. These distresses include well balanced diet, good sleep, and regular exercise. These ways for reducing stress should be promoted and encouraged in team members.

\section{f. Work relief}

Working hours should be reduced so as to reduce work stress on team.

\section{g. Rationality}

Team leader should develop rationality among the team. He should try to understand the emotions and feelings of team and should treat them according to their level.

\section{h. Flexibility}

Team leader should develop flexibility in his team to meet the varying working demands imposed by the project. If flexibility is not promoted the team cannot achieve the project goals, thus, reducing output and increasing psychological stress.

\section{i. Rejoice and encourage}

Factors like stressful projects, demanding stakeholders and deadlines cause the teams to undergo environmental stress. In order to avoid such problems teams should be given breaks and holidays for rejoicing. This brings a happier and healthier effect to team. 


\section{CONCLUSION}

In the past few years research has shown that the success rate of projects has increased evidently due to the involvement of Emotional intelligence. There are too many factors related to Emotional intelligence, different factors are useful in different types of projects, while this paper proposed a generic framework which can be applicable to all the projects. This paper starts from the basics of EI. Through the study of different articles, we find the beneficial EI elements which are required nowa-days and useful for project manager. Then after discussing the drawback of absence of these EI elements, provided a framework of EI for project manager to keep his team on right track. The proposed model that has been validated through this particular research determines that the EI elements have most significant role in disputing the challenges of project thereby enhancing the capabilities of PM.

There are still many fields of research available in Emotional Intelligence. If a project manager is involved in more than one project at the same time then improvement of his EI as well as his team is still a big challenge. To keep the interest of his team to different projects is very difficult job.

\section{REFERENCES}

[1] "Definitions, History and Measures of Emotional Intelligence",http://psychology.about.com/od/perso nalitydevelopment/a/emotionalintell.htm.

[2] John Keyser, "Emotional Intelligence is key to our Success", June 2013, http://www.astd.org/Publications/Blogs/WorkforceDevelopment-Blog/2013/06/EmotionalIntelligence-Is-Key-to-Our-Success.

[3] “Daniel Goleman's Five Components of Emotional

Intelligence",http://www.sonoma.edu/users/s/swijt ink/teaching/philosophy_101/paper1/goleman.htm.

[4] Joe Luca, PinaTerricone, "Does Emotional Intelligence Affect Successful Teamwork", http://www.ascilite.org.au/conferences/melbourne 01/pdf/papers/lucaj.pdf.

[5] Karen Davey, "Emotional Intelligence for Project Managers-Nice to have or Necessity", https://www.pmiwdc.org/article/karen-daveywinter/emotional-intelligence-project-managers--nice-have-or-necessity.

[6] "Helping your people develop Emotional Intelligence",http://www.mindtools.com/pages/arti cle/team-emotional-intelligence.htm.

[7] Nauman, S. Elahi, M. Bhatti, Z.A.Khalid, "Role of Emotional Intelligence in Virtual Project Management", Management of Innovation and Technology, 2006, IEEE.

[8] Barry, M.L.duPlessis, "Emotional intelligence: a crucial human resource management ability for engineering project managers in the 21 st century", AFRICON, 2007.

[9] Tang, Yin Mu-shang, "Emotional intelligence characteristics of IT professionals in Taiwan", IT in Medicine and Education, 2008. ITME 2008. IEEE.

[10] Li Lin, OuChanjuan,ZhengHuiyun, "Emotional Intelligence of Project Team", E-Business and Information System Security, 2009.

[11] Quinn, J.F.Wilemon, "Emotional intelligence as a facilitator of project leader effectiveness", Management of Engineering \& Technology, 2009. PICMET 2009.

[12] Rizvi, S.Z.R.Nisar, A.RazaNaqvi, S.K Waseem, M.Sadiq, "Healthy emotional intelligence and effective leadership", Industrial Engineering and Engineering Management (IE\&EM), 2011, IEEE.

[13] Amy Ohlendorf, "Conflict Resolution in Project Management",http://www.umsl.edu/ sauterv/anal ysis/488_f01_papers/Ohlendorf.htm.

[14] Dr. Zia Ahmed, "Stress and Conflict Management in Project Team", http://ziaahmedkhan.hubpages.com/hub/Stressand-Conflict-Management-in-Project-Team.

[15] Zwell, "Technical Skills vs Emotional Intelligence", http://zwell.com/?p=590.

[16] "Emotions and Emotional Intelligence", http://www.slideshare.net/renjith_sk/emotionalintelligence-its-role-in-leadership-andorganizational-success.

Engr. FaizaAyub Syed is a MS scholar as well as Research Associate in the Department of Software Engineering at University of Engineering and Technology Taxila, Pakistan. She graduated from University of Engineering and Technology Taxila in Software Engineering in July 2011. Her areas of interest are Software Design and Architecture, Digital Image Processing, Software Requirement Engineering, Software Quality Assurance, Computer Communication and Networks, Web Application Development and Desktop Application Development.

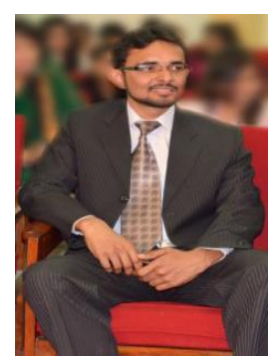

Engr. Adeel Rafiq is a MS Scholar as well as Research Associate in the Department of Software Engineering at University of Engineering and Technology Taxila, Pakistan. He graduated from COMSATS Institute of Information Technology WahCantt in Computer Engineering. After graduation he worked 13 months as a Software developer and web developer. His research interests are Digital Image Processing, Software Developing, Software Quality Assurance and Software Project Management. 


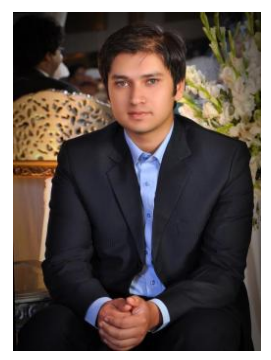

Engr. Bilal Ahsanis a MS Scholar as well as Research Associate in the Department of Software Engineering at University of Engineering and Technology Taxila, Pakistan. He graduated from COMSATS Institute of Information Technology Islamabad in Computer Engineering. After graduation he worked as a graphic designer and web developing. His research interests Digital Image Processing and Web Developing and Software Project Management.

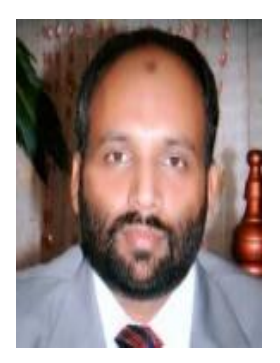

Muhammad Nadeem Majeed is an Assistant professor, software Engineering Department at University of Engineering \& Technology Taxila. He received his MS degree in Computer Engineering form Center for Advance studies in Engineering (CASE) in 2007. He is doing his $\mathrm{PhD}$ from University of Engineering and Technology Taxila, Pakistan. His areas of interest are Software Engineering, Project management, Communication and Networks and Vehicle ad-hoc Networks. 